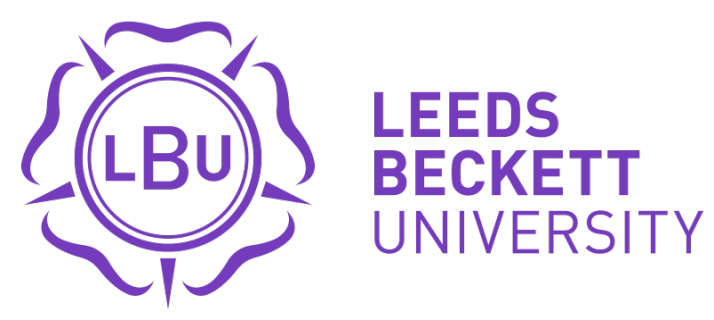

Citation:

Sagar, SS and Stoeber, J (2009) Perfectionism, fear of failure, and affective responses to success and failure: the central role of fear of experiencing shame and embarrassment. Journal of sport \& exercise psychology, 31 (5). 602 - 627. ISSN 0895-2779

Link to Leeds Beckett Repository record:

https://eprints.leedsbeckett.ac.uk/id/eprint/515/

Document Version:

Article (Accepted Version)

The aim of the Leeds Beckett Repository is to provide open access to our research, as required by funder policies and permitted by publishers and copyright law.

The Leeds Beckett repository holds a wide range of publications, each of which has been checked for copyright and the relevant embargo period has been applied by the Research Services team.

We operate on a standard take-down policy. If you are the author or publisher of an output and you would like it removed from the repository, please contact us and we will investigate on a case-by-case basis.

Each thesis in the repository has been cleared where necessary by the author for third party copyright. If you would like a thesis to be removed from the repository or believe there is an issue with copyright, please contact us on openaccess@leedsbeckett.ac.uk and we will investigate on a case-by-case basis. 
Sagar, S. S., \& Stoeber, J. (2009). Perfectionism, fear of failure, and affective responses to success and failure: The central role of fear of experiencing shame and embarrassment. Journal of Sport \& Exercise Psychology, 31(5), 602-627.

Perfectionism, Fear of Failure, and Affective Responses to Success and Failure:

The Central Role of Fear of Experiencing Shame and Embarrassment

\author{
Sam S. Sagar \\ Leeds Metropolitan University \\ Joachim Stoeber \\ University of Kent
}

Author Note

Sam S. Sagar, Department of Psychology, Leeds Metropolitan University, UK; Joachim Stoeber, Department of Psychology, University of Kent, UK. We thank Sophia Jowett, Kathleen Otto, and two anonymous reviewers for their helpful comments on an earlier version of this article. Correspondence concerning this article should be addressed to Sam Sagar, Department of Psychology, Faculty of Health, Leeds Metropolitan University, Leeds LS1 3HE, UK. Phone: +44-113-812 0000; Fax: +44-113-812 3440; Email: S.Sagar@leedsmet.ac.uk. 


\begin{abstract}
This study investigated how different aspects of perfectionism in athletes $(N=388)$ related to the different fears of failure proposed by Conroy et al. (2002), and how perfectionism and fears of failure predicted positive and negative affect after imagined success and failure in sports competitions. Results showed that perfectionistic personal standards showed a negative relationship with fear of experiencing shame and embarrassment and a positive relationship with positive affect after success, whereas perfectionistic concern over mistakes and perceived parental pressure showed a positive relationship with fear of experiencing shame and embarrassment and with negative affect after failure. Moreover, fear of experiencing shame and embarrassment fully mediated the relationship between perfectionistic concern and negative affect and between coach pressure and negative affect. The findings demonstrate that fear of experiencing shame and embarrassment is central in the perfectionism-fear of failure relationship and that perfectionistic concern about mistakes and perceived coach pressure are aspects of perfectionism that predict fear of experiencing shame and embarrassment and negative affect after failure.
\end{abstract}

Keywords: Personal Standards; Concern over Mistakes; Athletes; Fear; Coaches; Parents 
Perfectionism, Fear of Failure, and Affective Responses to Success and Failure:

The Central Role of Fear of Experiencing Shame and Embarrassment

Perfectionism is a personality disposition characterized by excessively high standards for performance and accompanied by tendencies for overly critical self-evaluations of one's behavior (Flett \& Hewitt, 2002; Frost, Marten, Lahart, \& Rosenblate, 1990). Although some view perfectionism as a characteristic that can help achieve elite sporting performance (e.g., Gould, Dieffenbach, \& Moffett, 2002) and enhance learning a new sporting skill (Stoll, Lau, \& Stoeber, 2008), others view perfectionism as a characteristic that undermines performance and represents an impediment to athletic development (e.g., Flett \& Hewitt, 2005; Hall, 2006).

Perfectionism is, however, a multidimensional and multifaceted construct (Frost et al., 1990; Hewitt \& Flett, 1991; see Enns \& Cox, 2002, for a review). Moreover, not all of its dimensions and facets are maladaptive. Indeed, some dimensions and facets may be positive. The most prevalent multidimensional models of perfectionism is that of Frost et al. (1990) and Hewitt and Flett (1991). Frost et al.'s model differentiates six dimensions of perfectionism: personal standards, concern over mistakes, parental expectations, parental criticism, doubts about actions, and organization. Hewitt and Flett's model differentiates three dimensions: self-oriented perfectionism, socially-prescribed perfectionism, and other-oriented perfectionism. Studies have shown that, when measures of the different dimensions of perfectionism are subjected to a factor analysis, two broad factors of perfectionism emerge (Frost, Heimberg, Holt, Mattia, \& Neubauer, 1993; see also Bieling, Israeli, \& Antony, 2004; Bieling, Israeli, Smith, \& Antony, 2003). The first factor comprises personal standards, organization, self-oriented perfectionism, and other-oriented perfectionism and was labeled "positive striving perfectionism". The second factor comprises concern over mistakes, parental expectations, parental criticism, doubts about actions, and socially-prescribed perfectionism and was labeled "maladaptive evaluation concerns perfectionism".

The reason for labeling one factor "positive" and the other factor "maladaptive" was that 
the two factors showed differential correlations: whereas maladaptive evaluation concerns perfectionism showed positive correlations with depression and negative affect, striving perfectionism showed a positive correlation with positive affect (Frost et al., 1993). Further studies have confirmed that the dimensions and facets from different measures of multidimensional perfectionism converge to two major dimensions and that the two dimensions often show different, sometimes opposite correlations (see Stoeber \& Otto, 2006, for a comprehensive review). This, however, is not always the case. The two dimensions can also show very similar correlations. Consequently, Stoeber and Otto (2006) recommended to refrain from labeling the two dimensions with evaluative terms (e.g., positive versus maladaptive) and instead refer to the two dimensions as "perfectionistic strivings" and "perfectionistic concerns."

The aim of the present study was to investigate how different aspects of multidimensional perfectionism in athletes—following Dunn et al.'s (2006) model and differentiating personal standards, concern over mistakes, perceived parental pressure, and perceived coach pressure—are related to fear of failure and how they predict affective responses to imagined success and failure in competitions.

\section{Perfectionism in Sport}

The differentiation between perfectionistic strivings and perfectionistic concerns is also important in the context of sport. There is converging evidence that the aspects of perfectionism associated with the perfectionistic strivings dimension of perfectionism (e.g., personal standards, striving for perfection) have shown positive correlations with positive characteristics, processes, and outcomes in athletes such as competitive self-confidence (Koivula, Hassmen, \& Fallby, 2002), approach goal orientations (Stoeber, Stoll, Pescheck, \& Otto, 2008), and training performance (Stoll et al., 2008). In contrast, the aspects of perfectionism associated with the perfectionistic concerns dimension (e.g., concern over mistakes, parental expectations and criticism) have shown positive correlations with athletes' competitive anxiety (e.g., Stoeber, Otto, Pescheck, Becker, \& Stoll, 2007), avoidance goal orientations (e.g., Stoeber, Stoll, et al., 2008), 
and burnout (e.g., Gould, Tuffey, Udry, \& Loehr, 1996; Gould, Udry, Tuffey, \& Loehr, 1996).

Whereas this pattern of findings largely mirrors that of the findings outside sport, Dunn and colleagues further argued that in sport, in addition to parents, there is another important source of evaluation concerns: the coach (Dunn, Dunn, \& Syrotuik, 2002). Consequently, Dunn and colleagues developed a multidimensional measure of perfectionism in sport (the Sport-MPS) that includes subscales to measure perceived parental pressure and perceived coach pressure (Dunn et al., 2006).

\section{Coaches and Parents as Sources of Perfectionistic Concerns}

Coaches and parents provide standards of acceptable performance among athletes and give evaluative feedback about athletes' ability and performance and, as such, their criticisms and expectations are a source of pressure and evaluation concerns for athletes (Anshel \& Eom, 2002; Dunn et al., 2006). It is, therefore, important to examine athletes' perceptions of both coach pressure and parental pressure when studying perfectionism in a social-evaluative context, such as sport, as it allows us to understand these aspects of perfectionism, which are interpersonal or socially prescribed (Dunn et al., 2006; Hewitt \& Flett, 1991).

The Sport-MPS (Dunn et al., 2002, 2006) assesses athletes' perceived coach pressure and perceived parental pressure through items pertaining to coaches' and parents' expectations and criticism. These two dimensions of perfectionism represent an interpersonal component of perfectionism in sport and are associated with the perfectionistic concerns dimension. Perceived coach/parents pressure assesses (a) the degree to which athletes perceive their coach/ parents to set high performance standards for them, and (b) their coach/ parents to be overly critical of their performance after failing to achieve those high standards. Coaches' criticism and other punitive behaviors (e.g., using fear and intimidation, shouting) have been associated with athletes' stress (Underwood, 1978), low perceived competence and motivation (Amorose \& Horn, 2000), fear of making mistakes, evaluation apprehension, and high anxiety and worry levels (Gould, Horn, \& Spreemann, 1983; Lewthwaite \& Scanlan, 1989). 
Parents are a source of perfectionistic concerns through their high expectations and critical evaluation of their child, and the child's tendency to place substantial value on their parents' evaluation (Frost et al., 1990; Hewitt \& Flett, 1991). Parental high expectations and criticism (or negative evaluation) of their child's achievement have been associated with the development of fear of failure in children (Schmalt, 1982; Teevan \& McGhee, 1972), and with children's feelings of shame and guilt when not meeting parental expectations (Lewis, 1992). Perceived parental and coach pressure have been linked to young athletes' burnout (as they feel obligated to continue to fulfill their expectations) (Gould, Tuffey, et al., 1996; Gould, Udry, et al., 1996), dropout from sport (Pelletier, Fortier, Vallerand, \& Briere, 2001; T. T. Robinson \& Carron, 1982), and cognitive anxiety symptoms that are related to pre-competitive worries about failure, upsetting parents and coaches, coaches' and parents' negative evaluation, and pressure to avoid mistakes (Lewthwaite \& Scanlan, 1989).

\section{Perfectionism and Fear of Failure}

Perfectionistic concerns have shown close links with fear of failure in athletes (e.g., Frost \& Henderson, 1991; Stoeber \& Becker, 2008). The relationship between perfectionism in sport and fear of failure is evidenced in findings that indicate that aspects from both dimensions of perfectionism—perfectionistic strivings and perfectionistic concerns—show positive correlations with fear of failure, suggesting that fear of failure is associated with all aspects of perfectionism (e.g., Kaye, Conroy, \& Fifer, 2008). A more detailed look, however, reveals that it is predominantly the aspects of the evaluative concerns dimension of perfectionism that show consistent positive correlations with fear of failure.

An early study with college athletes looking into multidimensional perfectionism and motivational orientations (Frost \& Henderson, 1991) found that both perfectionistic personal standards and perfectionistic concern over mistakes showed positive correlations with failure orientation towards competition. The positive correlation of personal standards was, however, significantly smaller than that of concern over mistakes. Moreover, personal standards showed a 
significantly larger positive correlation with success orientation than concern over mistakes, indicating that perfectionistic concerns are more closely associated with fear of failure, whereas perfectionistic strivings are more closely associated with hope of success. This was corroborated by a recent study that investigated hope of success and fear of failure in female soccer players (Stoeber \& Becker, 2008). Results revealed that only negative reactions to imperfection (an aspect of evaluative concerns perfectionism) showed positive correlations with fear of failure, whereas striving for perfection (an aspect of personal standards perfectionism) showed a positive correlation with hope of success. Moreover, when the influence of negative reactions to mistakes was partialled out, striving for perfection showed a negative correlation with fear of failure. Fears of Failure

Fear of failure is a motive to avoid failure in evaluative situations based on anticipatory shame upon failure (Atkinson, 1957; McClelland, Atkinson, Clark, \& Lowell, 1953). However, contemporary theorists, unlike early theorists, do not conceptualize fear of failure as a unidimensional construct, but as a multidimensional construct — as evidenced in Conroy and colleagues' multidimensional model (Conroy, Willow, \& Metzler, 2002). Conroy and colleagues view fear of failure as the tendency to appraise threat to the achievement of personally meaningful goals when one fails in the performance. They suggest that failure is perceived as threatening, and feared, by individuals who associate it with aversive consequences (Conroy et al., 2002; see also Sagar, Lavallee, \& Spray, 2007). Their model proposes five beliefs about the consequences of failure that are associated with threat appraisal and feared. To measure these beliefs, Conroy and colleagues developed the Performance Failure Appraisal Inventory (PFAI; Conroy et al., 2002) which differentiates five fears of failure: fear of experiencing shame and embarrassment, fear of devaluing one's self-estimate, fear of having an uncertain future, fear of important others losing interest, and fear of upsetting important others.

Two recent studies have investigated how different aspects of perfectionism in athletes relate to the different fears of failure of Conroy et al.'s (2002) multidimensional model. The first 
study (Conroy, Kaye, \& Fifer, 2007) investigated self-oriented perfectionism (an aspect of perfectionistic strivings) and socially prescribed perfectionism (an aspect of perfectionistic concerns) among college students who participated in physical activity classes. Bivariate correlations between perfectionism and fear of failure revealed that the two forms of perfectionism showed similar correlations; socially prescribed perfectionism showed positive correlations with all five fears of failure, and self-oriented perfectionism showed positive correlations with four of the five fears of failure (the correlation with fear of having an uncertain future was nonsignificant). However, when regression analyses were computed, only socially prescribed perfectionism was associated with fear of important others losing interest and fear of upsetting important others (these were classified as aversive interpersonal consequences of failure), whereas self-oriented perfectionism did not show any associations. These findings suggest that the perfectionistic concerns dimension of perfectionism shows close links to fears of failure, not the perfectionistic strivings dimension. The authors concluded that the desire to be perfect and avoid failure involved complex cognitive and behavioral factors and that the multidimensionality of perfectionism is best described in terms of perfectionistic concerns and strivings components.

This was confirmed and further extended by the second study (Kaye et al., 2008) that examined how perfectionistic personal standards (the marker variable of personal standards perfectionism) and perfectionistic concern over mistakes (the marker variable of evaluative concerns perfectionism) related to the five fears of failure. Moreover, perceived parental pressure-representing athletes' perception that their parents expect them to be perfect and criticize them if they are not (Stöber, 1998; Stumpf \& Parker, 2000)—was investigated. When bivariate correlations were inspected, perfectionistic personal standards showed positive correlations only with fear of important others losing interest and fear of experiencing shame and embarrassment. In contrast, perfectionistic concern over mistakes showed positive correlations with all five fears of failure, as did perceived parental pressures. Moreover, personal standards 
showed a positive correlation with positive affect whereas concern over mistakes, parental pressure, and all five fears of failure showed positive correlations with negative affect. In sum, the findings indicate that it is mainly concern over mistakes and perceived pressure to be perfect that are linked to fear of failure, and not perfectionistic personal standards. Whereas personal standards appear to be a more positive aspect of perfectionism (cf. Stoeber \& Otto, 2006), perfectionistic concern over mistakes and perceived pressure to be perfect are closely linked to fear of failure and negative affect.

Perfectionism and Affect After Success and Failure

Emotions are central aspects of people's lives (both interpersonally and intrapersonally) and can have powerful impacts (positive and negative) on their functioning (Lazarus, 1991). In sport, being successful (through winning) produces a range of pleasant affective outcomes (e.g., pride, gratitude, excitement), whereas failure (through losing) produces strong unpleasant affect (e.g., shame, guilt, anger, anxiety; Wilson \& Kerr, 1999). Fear of failure has been shown to elicit negative affect in athletes (e.g., worry, stress, somatic and cognitive anxiety; Conroy \& Metzler 2004; Conroy et al., 2002) and to affect their well-being, interpersonal behavior, and sporting performance (Sagar, Lavallee, \& Spray, 2009). Emotions (e.g., anxiety, anger, pride, guilt, shame) have also been investigated in relation to perfectionism and success and failure. Researchers have posited that perfectionists measure their self-worth in terms of accomplishment and are overly self-critical of their behavior and achievements and, therefore, are prone to experiencing shame and guilt and are unable to experience pride (e.g., Alden, Bieling, \& Wallace, 1994; Dunkley, Zuroff, \& Blankstein, 2003). Shame, guilt and pride are self-conscious emotions that involve the evaluation of the self (Tangney, 2002); shame and guilt relate to negative self-evaluation.

Perfectionistic strivings (e.g., self-oriented perfectionism) have been generally associated with positive affect (e.g., pride), whereas perfectionistic concerns (e.g., socially prescribed perfectionism) has been associated with negative affect (Molnar, Reker, Culp, Sadava, \& DeCourville, 2006; Stoeber \& Otto, 2006), psychological distress after failure (e.g., negative 
mood, anxiety; Hewitt, Flett, Besser, Sherry, \& McGee, 2003) and proneness to shame and guilt (Klibert, Rohling, \& Saito, 2005; Lutwak \& Ferrari, 1996), more than perfectionistic strivings (Hewitt \& Flett, 1991; Lutwak \& Ferrari, 1996). Finally, a study that examined performance in a choice reaction-time task reported perfectionistic strivings to show negative cognitive (i.e., performance dissatisfaction, cognitive rumination, and irrational task importance) and affective reactions (i.e., anxiety, dysphoria, and hostility) following failure experiences (i.e., negative performance feedback) that reflect poorly on the self (Besser, Flett, \& Hewitt, 2004).

\section{The Present Research}

These studies, however, leave open questions. First, personal standards, concern over mistakes, and parental pressure are all highly correlated (Dunn et al., 2002, 2006; Stöber, 1998; Stumpf \& Parker, 2000). Consequently, it remains unclear whether the three aspects of perfectionism show unique relationships with the different fears of failure of Conroy et al.'s (2002) model. Second, in addition to parents, coaches are important sources of pressure to be perfect for athletes high in perfectionism (Dunn et al., 2002, 2006). It is, therefore, important to examine these factors when studying athletes' perfectionism and fear of failure. Finally, Kaye et al. (2008) investigated only general positive and negative affect, and not positive and negative affective responses to sport-specific events such as competitions. Success in competitions (through winning) evokes strong positive emotions, whereas failure (through losing) evokes strong negative emotions (Wilson \& Kerr, 1999). Consequently, questions remain whether perfectionism and fear of failure predict how athletes would feel when experiencing success and failure in important competitions.

Against this background, the present study had three main aims. The first aim was to investigate the unique relationships between perfectionistic personal standards and concern over mistakes with the five fears of failure of Conroy et al.'s (2002) model. In line with previous findings (Kaye et al., 2008), we expected only concern over mistakes, but not personal standards, to be related to all five fears of failure. The second aim was to investigate perceived coach 
pressure and compare it to perceived parental pressure regarding differential relationships with the five fears of failure. As perceived coach pressure may be more relevant to adult athletes (compared to junior athletes) than perceived parental pressure (Dunn et al., 2006), we expected perceived coach pressure to show closer relationships with athletes' fears of failure and their affective reactions to success and failure than parental pressure. The third aim was to investigate how the different aspects of perfectionism and the different fears of failure predicted positive and negative affect after success and failure in an important competition. Regarding perfectionism, we expected that perfectionistic personal standards would predict higher levels of positive affect after success, whereas concern over mistakes and perceived parental and coach pressure would predict higher levels of negative affect after failure (cf. Stoeber, Kempe, \& Keogh, 2008). Regarding fear of failure, we expected that all fears of failure would show positive correlations with negative affect after failure (cf. Kaye et al., 2008), but fear of experiencing shame and embarrassment would show the strongest degree of relationship with high levels of affect after failure. As we expected concerns over mistakes to predict fear of failure and negative affect, and fear of failure to predict negative affect, we additionally examined the relationship between perfectionism, fear of failure, and affective responses to success and failure, by means of mediational analyses, to explore whether fear of failure mediated the relationship between perfectionism and negative affective responses to failure.

\section{Method}

\section{Participants}

A sample of 388 athletes (208 male, 180 female) was recruited from the student body of a British university with a renowned sporting orientation. Athletes were on average $M=20.7$ years old $(S D=1.8$ years; range $=18-27$ years $)$ and had been active in their sports for $M=7.8$ years $(S D=4.7$ years; range $=1-19$ years $)$. Asked in what type of sports they competed, athletes indicated rugby (11\% of athletes); football (soccer) and athletics ( $8 \%$ each); taekwondo (7\%); lacrosse, basketball, and triathlon ( $6 \%$ each); badminton, netball, hockey, and rowing ( $5 \%$ each); 
kung fu (4\%); gymnastics, volleyball, fencing, kickboxing, and trampoline (3\% each); tennis, archery, karate, and cricket (2\% each); and judo (1\%). Asked to indicate the highest levels at which they competed, athletes indicated that they competed at university level (35\%), club level (20\%), regional level (13\%), national level (19\%), and international level (13\%).

\section{Procedures}

After obtaining permission from the university athletic body and the head coaches, athletes were approached by the first author, prior to their training sessions, asking them if they would volunteer for the study. The study's aims, its voluntary nature, and the criterion for participation (to be actively competing in their sport at the time of the study) were explained to the athletes. After signing an informed consent form, the athletes completed the questionnaire that contained the measures described below.

Measures

Perfectionism. To capture aspects of both perfectionistic strivings and perfectionistic concern, we measured four aspects of perfectionism: personal standards, concern over mistakes, perceived parental pressure, and perceived coach pressure. To measure personal standards and concern over mistakes, we used the Personal Standards and Concern over Mistakes subscales of the Sport Multidimensional Perfectionism Scale (Sport-MPS; Dunn et al., 2002). The Sport-MPS was chosen because it is the most widely used sport-specific measure of perfectionism and has been tested in a number of studies demonstrating high reliability and validity (e.g., Dunn et al., 2006; Dunn et al., 2002; Vallance, Dunn, \& Dunn, 2006). The Personal Standards scale consists of seven items measuring perfectionistic personal standards (e.g., "I have extremely high goals for myself'), and the Concern Over Mistakes subscale consists of eight items measuring perfectionistic concern over mistakes (e.g., "People will probably think less of me if I make mistakes in competition”). To measure perceived parental pressure and perceived coach pressure, we used the Perceived Parental Pressure and the Perceived Coach Pressure subscales from the English version of the Multidimensional Inventory of Perfectionism in Sport (MIPS; Stoeber, 
Otto, \& Stoll, 2005) which was translated from the original German version (Stoeber, Otto, \& Stoll, 2004) to English using a back-translation procedure involving two bilingual speakers (one native English, one native German; see Brislin, Lonner, \& Thorndike, 1973). The reason for choosing the MIPS scales (and not the respective Sport-MPS scales) was that the MIPS scales have the same number of items and the same item content measuring parental pressure and coach pressure (see items in the Appendix). Consequently, only the MIPS scales allow for a direct comparison of different sources of perceived pressure to be perfect (cf. Stoeber \& Eismann, 2007: talented young musicians' perceived pressure from music teacher vs. parents; Stoeber \& Rennert, 2008: school teachers' perceived pressure from colleagues vs. students vs. students' parents). Items were answered on a seven-point scale from 1 ("strongly disagree") to 7 ("strongly agree"), and scores were computed by averaging across items. With Cronbach's alphas $>.80$ (see Table 1), all scores showed high reliability (Nunnally \& Bernstein, 1994).

Fear of failure. To measure fear of failure, we used the Performance Failure Appraisal Inventory (PFAI; Conroy et al., 2002). The PFAI consists of 25 items measuring beliefs associated with aversive consequences of failure. The PFAI has five subscales capturing fear of experiencing shame and embarrassment (7 items; e.g., "When I am failing, it is embarrassing if others are there to see it"), fear of devaluing one's self-estimate (4 items; e.g., "When I am failing, I blame my lack of talent"), fear of important others losing interest (5 items; e.g., "When I am not succeeding, people are less interested in me"), fear of upsetting important others (5 items; "When I am failing, people who are important to me are disappointed"), and fear of having an uncertain future (4 items; e.g., 'When I am failing, it upsets my 'plan' for the future”). Participants rated how strongly they believed each consequence was likely to happen to them after failure in competition. Items were answered on a five-point scale from 0 (“do not believe it at all") to 4 ("believe it $100 \%$ of the time"), and scores were computed by averaging across items. With Cronbach's alphas $>.70$ (see Table 1), all scores showed satisfactory reliability (Nunnally \& Bernstein, 1994). 
Affect. To investigate affective responses to success and failure, we employed a scenariobased method to stimulate imagined affective response in athletes to success and failure experiences in sports competitions. Two scenarios were created for this study using vignettes: one success scenario, and one failure scenario. Participants were instructed to imagine their reaction to these scenarios happening to them, and to answer the questions that followed by choosing the most accurate response for them from the options listed. Eliciting affective response to scenarios has been reported to be a valid method of indicating affective responses in real life, showing convergence of real and imagined reactions to emotional stimuli (see Carver, 2004; M. D. Robinson \& Clore, 2001) and has provided evidence for developing appraisal theories of emotion (Parkinson \& Manstead, 1993).

Two scenarios were presented: a success scenario and a failure scenario. To counterbalance the sequence of success versus failure, half of the participants $(n=194)$ received first the success scenario and then the failure scenario (sequence $=$ success-failure) and half of the athletes $(n=194)$ received first the failure scenario and then the success scenario (sequence $=$ failure-success). For the participants in the success-failure condition, the success instruction read: "Success! Imagine that you are participating in an important sport competition. You have set yourself a certain level of performance that you want to achieve in this competition. In the competition, you try your best—and you are successful in achieving the level of performance that you aspired to. How would you feel?" The failure instruction read: "Failure! Now imagine the same situation: you are participating in an important sport competition. You have set yourself a certain level of performance that you want to achieve in this competition. In the competition, you try your best—-but you fail to achieve the level of performance that you aspired to. How would you feel?" For the participants in the failure-success condition, the instructions were exactly the same except that the failure instruction began with "Failure! Imagine you are participating in an important sport competition." and the success instruction with "Success! Now imagine the same situation." 
To measure positive and negative affect, we used Nezlek's (2005) instrument of positive and negative affect. The scale consists of 20 items of which 10 measure positive affect (e.g., happy, satisfied, relaxed) and 10 negative affect (e.g., embarrassed, depressed, disappointed). Participants rated their affective responses on a five-point scale from 0 ("not at all") to 4 ("extremely"). Focusing on positive affect after success and negative affect after failure (because we had no expectations regarding negative affect after success and positive affect after failure, and few athletes reported such emotions), scores were computed by averaging across items. With Cronbach's alphas $>.70$ (see Table 1$)$, both scores showed satisfactory reliability (Nunnally \& Bernstein, 1994).

Preliminary Analyses

To investigate whether data could be collapsed across gender (male, female) and sequence (success-failure, failure-success), we examined whether the variance-covariance matrices were the same across gender and sequence using Box's $M$ test. As this test is highly sensitive to even small differences in the variance-covariance matrices between groups, a significance level of $p<$ .001 is recommended (Tabachnick \& Fidell, 2007). For both gender and sequence, Box's $M$ test was nonsignificant: for gender, Box's $M$ was 100.00, $F(66,455528)=1.47, p=.008$; and for sequence, it was $79.45, F(66,475079)=1.17, p=.165$. Consequently, data were collapsed across gender and sequence.

To investigate whether success and failure scenarios produced differential affective reactions, we examined the mean scores of positive and negative affect after success and failure. As intended, positive affect was markedly higher after success $(M=2.96 ; S D=0.54)$ than after failure $(M=0.85 ; S D=0.72), F(1,387)=1947.60, p<.001$, and negative affect was markedly higher after failure $(M=2.14 ; S D=0.79)$ than after success $(M=0.53 ; S D=0.57), F(1,387)=$ $1190.55, p<.001$, confirming that the scenarios were successful in manipulating affective responses to success and failure in the expected direction. 
To investigate our hypotheses, we first computed correlations to inspect the associations between all variables. Next, we computed two sets of hierarchical regression analyses predicting positive and negative affect after success and failure—one set in which perfectionism predicted affect, and one set in which fear of failure predicted affect - to examine what factors of the constructs made unique predictions of positive and negative affect after success and failure. Finally, to examine whether fear of failure mediated the relationship between perfectionism and affective responses to success and failure, we computed hierarchical regression analyses with perfectionism and fear of failure as predictors. In this, we followed Baron and Kenny's (1986) regression approach according to which a mediation effect has to meet three conditions: (a) the independent variable significantly predicts both the presumed mediator variable and the dependent variable; (b) the mediator variable significantly predicts the dependent variable; and (c) when the influence of the mediator variable is controlled for, the previously significant relationship between independent variable and dependent variable is no longer significant. Because this approach does not provide a direct test of mediation, we additionally computed Sobel tests and bootstrapping tests, as recommended by Shrout and Bolger (2002), using the procedures provided by Preacher and Hayes (2004).

\section{Results}

\section{Correlation Analyses}

Following our analytic strategy, we first computed bivariate correlations (see Table 1). Regarding perfectionism and fear of failure, results showed that perfectionism was correlated with fear of failure in competition. All aspects of perfectionism showed positive correlations with the different fears of failure corroborating previous findings that fear of failure is a dominant theme in athletes with high levels of perfectionism. For correlations, Cohen (1992) considers $r=$ .10 to represent a small-sized, $r=.30$ a medium-sized, and $r=.50$ a large-sized effect.

Accordingly, concern over mistakes showed medium- to large-sized correlations with all fears ranging from .42 to .51 , whereas personal standards showed small- to medium-sized correlations 
ranging from .21 to .32 , and perceived parental and perceived coach pressure showed small- to medium-sized correlations from .12 to .40 (see Table 1). Regarding affective responses to success and failure, however, the pattern was more differentiated. Whereas all facets of perfectionism showed positive correlations with negative affect after failure (ranging from .11 to .30), personal standards and perceived coach pressure also showed small positive correlations with positive affect after success. In line with findings that perfectionistic strivings are associated with positive affect after success (Stoeber, Kempe, \& Keogh, 2008), athletes with high levels of perfectionistic personal standards imagined higher levels of positive affect after success than athletes with lower personal standards. Moreover, athletes who perceived higher levels of coach pressure to be perfect imagined more positive affect after success than athletes who perceived lower pressure. Finally, regarding fear of failure and affect, fear of failure was not correlated with positive affect after success. All five fears of failure, however, showed small- to medium-sized positive correlations with negative affect after failure (ranging from .20 to .48).

Regression Analyses

Following our analytic strategy, we computed three sets of regression analyses. First, we investigated which aspects of perfectionism made unique contributions to the different fears of failure (see Table 2). Results showed that only perfectionistic concern over mistakes showed significant positive regression weights in the regression analyses of all five fears of failure. The other aspects of perfectionism, however, showed more differentiated relationships. Both perceived parental pressure and perceived coach pressure showed positive regression weights with fear of upsetting important others. However, only parental pressure predicted fear of having an uncertain future, and only coach pressure predicted fear of experiencing shame and embarrassment. In contrast, personal standards showed a negative regression weight in the prediction of fear of experiencing shame and embarrassment. Overall, perfectionism explained between 20\% (fear of having an uncertain future) and 32\% (fear of upsetting important others) of the variance of the different fears of failure. For multiple regressions, Cohen (1992) calculates 
the effect size $f=R^{2} /\left(1-R^{2}\right)$ and considers $f=.02$ a small, $f=.15$ a medium, and $f=.35$ a large effect. Consequently, with effect sizes between $\rho=.27$ and $\rho=.47$, perfectionism showed medium- to large-sized effects in the regressions predicting fears of failure.

Second, we investigated which aspects of perfectionism made unique contributions in the prediction of how athletes imagined responding to success and failure (see Table 3). Results showed a clearly differentiated pattern. Whereas personal standards predicted positive affect after success, concern over mistakes predicted negative affect failure. Perceived parental pressure made no unique contribution to the prediction of affective responses to the success or failure. In contrast, perceived coach pressure predicted both positive affect after success and negative affect after failure. Note, however, that perfectionism overall explained only $3 \%$ of variance in positive affect after success (corresponding to $f^{2}=.03$, a small-sized effect), whereas perfectionism explained $11 \%$ of variance in negative affect after failure (corresponding to $f=.12$, a mediumsized effect), indicating that perfectionism is a stronger predictor of negative affect after failure than of positive affect after success.

Finally, we investigated which fears of failure made unique contributions in the prediction of affective responses to success and failure (see Table 4). As expected, fear of experiencing shame and embarrassment was the strongest predictor of negative affect after failure. Moreover, it was the only significant predictor. Note, however, that the bivariate correlation of fear of experiencing shame and embarrassment with positive affect was nonsignificant (see Table 1) as was the overall model of fear of failure predicting positive affect (see Table 4, Note). Consequently, this effect should be regarded with caution. Moreover, the different fears of failure explained only $2 \%$ of variance in positive affect after success (corresponding to $f^{2}=.02$, a smallsized effect), whereas they explained $24 \%$ of variance in negative affect after failure (corresponding to $\mathcal{f}=.32$, a large-sized effect). This indicates that, as was expected, fear of failure is a stronger predictor of negative affect after failure than of positive affect after success. 
Regarding the findings displayed in Tables 2 to 4, two constellations suggested possible mediation effects according to the criteria outlined by Baron and Kenny (1986). The first constellation was that fear of experiencing shame and embarrassment predicted negative affect (Table 4) and concern over mistakes predicted fear of experiencing shame and embarrassment and also negative affect (Table 2 and 3). The second was that fear of experiencing shame and embarrassment predicted negative affect (Table 4) and perceived coach pressure predicted both fear of experiencing shame and embarrassment and negative affect (Table 2 and 3). To test whether the relationships of concern over mistakes and perceived coach pressure with negative affect after failure were mediated by fear of experiencing shame and embarrassment, we computed two sets of regression analyses (see Baron \& Kenny, 1986). In the first set, negative affect served as the dependent variable, concern over mistakes served as the independent variable, and fear of experiencing shame and embarrassment served as the mediator variable. In the second set, negative affect served as the dependent variable, perceived coach pressure served as the independent variable, and fear of experiencing shame and embarrassment served as the mediator variable.

The results showed that the fear of experiencing shame and embarrassment fulfilled Baron and Kenny's (1986) three conditions for a mediation effect for both perfectionistic concerns and perceived coach pressure (see Figure 1): (a) concerns over mistakes and perceived coach pressure significantly predicted both fear of failure and negative affect after failure; (b) fear of failure significantly predicted negative affect after failure; and (c) when the influence of fear of failure was controlled for, the previously significant relationships between concerns over mistakes and perceived coach pressure with negative affect after failure were no longer significant. Moreover, when the mediation effects were tested with the procedures provided by Preacher and Hayes (2004), all tests were significant. Regarding the mediation effect for concern over mistakes (Figure 1, Panel A), the Sobel test was significant with $z=7.20, p<.001$ and the $95 \%$ confidence interval (CI) of the bootstrapped indirect effect did not include zero (95\% CI $=.23-.41)$. 
Regarding the mediation effect for perceived coach pressure (Figure 1, Panel B), the Sobel test was significant with $z=4.10, p<.001$ and the $95 \%$ confidence interval $(\mathrm{CI})$ of the bootstrapped indirect effect did not include zero (95\% CI $=.11-.36)$ (see Preacher \& Hayes, for details). Overall the results showed that fear of experiencing shame and embarrassment fully mediated the relationship between perfectionistic concern over mistakes and negative affect after failure and between perceived coach pressure and negative affect after failure. Moreover, the mediation models accounted for a substantial percentage of variance in negative affect after failure: both mediation models explained 24\% variance in negative affect after failure (see caption of Figure 1) which correspond to a large-sized effect $(f=.32)$.

\section{Discussion}

The aim of the present study was to further investigate the relationships between perfectionism, fear of failure, and affective responses to success and failure in athletes. In this, we examined the relationships of four different aspects of perfectionism—personal standards, concern over mistakes, perceived parental pressure, and perceived coach pressure (Dunn et al., 2002; Stoeber et al., 2005)—and five different fears of failure: fear of experiencing shame and embarrassment, fear of devaluing one's self-estimate, fear of having an uncertain future, fear of important others losing interest, and fear of upsetting important others (Conroy et al., 2002). Results from regression analyses showed that concern over mistakes predicted higher levels of all fears of failure whereas, when all aspects of perfectionism were considered simultaneously, personal standards predicted lower fear of experiencing shame and embarrassment, corroborating previous findings that aspects associated with personal standards perfectionism are associated with lower fear of failure (Stoeber \& Becker, 2008). In contrast, perceived coach pressure predicted higher fear of experiencing shame and embarrassment. Moreover, both perceived coach pressure and perceived parental pressure predicted higher fear of upsetting important others. However, only perceived parental pressure predicted higher fear of having an uncertain future. 
Regarding affective responses to success and failure scenarios, personal standards predicted positive affect after success and concern over mistakes predicted negative affect after failure, as was expected (Stoeber, Kempe, \& Keogh, 2008). In addition, perceived coach pressure emerged as an important factor determining the affective responses to success and failure by predicting both positive affect after success and negative affect after failure. Finally, when mediational analyses were conducted to further examine the relationship between perfectionism, fear of failure, and negative affect after failure, results showed that fear of experiencing shame and embarrassment fully mediated the relationship between perfectionistic concern over mistakes and negative affect after failure, and between perceived coach pressure and negative affect after failure.

The findings have important implications for research on athletes' perfectionism, fear of failure, and affective responses to success and failure in sports competition. First, they corroborate previous findings that, while closely related to negative aspects of perfectionism, perfectionistic personal standards when regarded alone are an aspect of perfectionism that is associated with positive characteristics, processes, and outcomes (Koivula et al., 2002; Stoeber, Stoll, et al., 2008). Our results showed that perfectionistic personal standards had only positive effects (once the overlap with the other aspects of perfectionism was controlled for). Not only did personal standards predict less fear of experiencing shame and embarrassment, they also predicted more positive affect after failure. As such, it is important to distinguish between perfectionistic strivings and perfectionistic concerns and to recognize that the former can be adaptive and healthy only when athletes accept their imperfections (i.e., failures, mistakes, shortcomings; Lundh, Saboonchi, \& Wångby, 2008). Conversely, perfectionistic strivings can be unhealthy and maladaptive when athletes "turn striving for perfection into a demand for perfection" and are unable to accept imperfection (Lundh et al., 2008, p. 255), and when their self-worth is contingent on achieving perfection (DiBartolo, Frost, Chang, LaSota, \& Grills, 2004; Dunkley, Zuroff, \& Blankstein, 2006). 
Sport is a continually evaluative environment and while we recognize the need for athletes and coaches to set high standards and strive for perfection in sport performance (Clements, 2008), it is imperative that both do not put down the athletes' efforts, performance, and selfworth when the results are imperfect. Moreover, if practitioners can identify and challenge the maladaptive perfectionistic thoughts and behaviors of perfectionistic athletes (see Antony \& Swinson, 1998; Pleva \& Wade, 2007), help them learn to pursue perfection independent of selfworth, and cope with the negative aspects of perfectionism, perfectionistic strivings need not be maladaptive and impair the athletes' performance. Indeed, it can contribute to their positive motivational orientations (Stoeber, Stoll, Salmi, \& Tiikkaja, 2009). Finally, practitioners can train coaches to recognize signs of maladaptive perfectionism in athletes and help enhance their sport performance and development, as well as their sporting experiences and well-being.

Secondly, the findings show that, when investigating perfectionism in athletes, it is vital to account for perceived coach pressure (Dunn et al., 2002, 2006). Previous researchers have shown that perceived pressure from significant others (i.e., parents and coaches) is closely related to perfectionistic concerns (e.g., Dunn et al., 2006) and to fears of failure (e.g., Kaye et al., 2008), suggesting that significant others-by pressuring athletes to perform perfectly, to avoid mistakes, and to meet high expectations, and by criticizing them when they fail to meet these expectations - contribute to the development of athletes' fear of failure. Our findings, however, indicate that perceived pressure from coaches may be more significant for athletes than perceived pressure from parents. This can be attributed to the fact that coaches, more than parents, have a direct influence on adult athletes as they evaluate their performances (Dunn et al., 2006). As such, adult athletes may strive and focus on meeting their coaches' expectations and performance standards more than on their parents'. Perceived parental pressure was associated with fear of upsetting important others and fear of having an uncertain future, both of which have been linked to decreased self-affirmation and increased hostile self-talk (e.g., self-blame, self-attack, self-neglect) after failure (Conroy, 2004). However, only perceived coach pressure (but not 
perceived parental pressure) predicted athletes' affective reactions to success and failure. This finding indicates that the coach is a central source of perceived pressure to be perfect and is closely related to how athletes feel after competitions. In this, however, perceived coach pressure seems to be a double-edged sword: athletes who perceived that their coach expected them to be perfect experienced more positive emotions after success (e.g., happy, proud, satisfied), but also experienced more negative emotions after failure (e.g., embarrassed, disappointed, sad) compared to athletes who perceived their coach as having less demanding standards. In light of our findings, and given that coaches' actual behaviors influence athletes' perception of pressure (Smith \& Smoll, 2007), there is a great value in educational interventions designed to train coaches to provide less critical and negative evaluations and more positive and supportive athletic environments that embrace athletes' mistakes and failures and help reduce athletes' concerns over mistakes and fear of failure.

Finally, our findings showed that fear of experiencing shame and embarrassment is central to understanding the relationships between perfectionism, fear of failure, and negative affect after failure in competition. Shame is an emotion at the core of fear of failure (McGregor \& Elliot, 2005) and involves a negative scrutiny of the entire self and feelings of incompetence (Tangney, 2002). Shame is a painful experience because it is associated with feeling that one's entire self is a failure and makes one seek an escape from the shame-eliciting situation (Lewis, 1992; Tangney, 2002). Shame and embarrassment occur when one concludes, through cognitive processes of self-evaluation, that one has failed. Perfectionists—particularly those high in perfectionistic concerns - may be especially vulnerable to experiencing shame and embarrassment as they orient towards and focus greatly on self-evaluation. Their perceptions and interpretation of the meaning and implications of their mistakes and failures may lead them to experience shame and embarrassment when they make mistakes and fail. They tend to equate perfect performance with self-worth and failure as a sign of being worthless (Tangney, 2002). Accordingly, athletes' interpretations of their mistakes and performances as failure can have negative implication for 
them, especially for perfectionistic athletes who typically strive to achieve high standards of performance and are concerned about mistakes and others' negative evaluation. Sporting performances typically take place in public arenas and, as such, mistakes and failures expose the athletes both to others' negative evaluation as well as to their own negative self-evaluation. This can elicit fear of failure, specifically fear of experiencing shame and embarrassment upon failure. Accordingly, it explains our finding that fear of experiencing shame and embarrassment is central in the perfectionism-fear of failure relation.

According to Lazarus (1991), emotions are linked to motives and cognitions (or schemas) and result from the interaction of personality and environment, and are connected to types of ego-involvement (or self-identities). Lazarus proposed shame and embarrassment to result from a failure to live up to one's ego-ideal, which is an image of personal excellence that one strives for; thus shame is associated with perceptions of personal failure and self-deficiency. As such, we assume that many athletes' ego-ideals include the image of themselves as athletically competent or even excellent or the best at their sporting pursuit and, therefore, we would expect athletes to perceive failure as shameful and to fear it. It is important to note, however, that our findings indicate that higher fear of experiencing shame and embarrassment explains the relationship between perfectionism and negative affect after failure. Both concern over mistakes and perceived coach pressure predicted negative affect after failure, and in both cases fear of experiencing shame and embarrassment fully mediated this relationship (see Figure 1).

The present study has some limitations. First, we followed Dunn et al.'s (2002, 2006) model of multidimensional perfectionism in athletes investigating four central aspects: personal standards, concern over mistakes, perceived coach pressure, and perceived parental pressure. While this model is based on Frost et al.'s (1990) multidimensional model and adds an important aspect (perceived coach pressure), it excludes two other aspects that are included in Frost's model: organization and doubts about actions. Perfectionism research with non-athletes has long recognized organization to be a positive and doubts about actions to be a negative aspect of 
multidimensional perfectionism (e.g., Frost et al., 1993), but only recently a sport-specific measure of perfectionism has become available that considers these two aspects (Gotwals \& Dunn, in press). Consequently, future studies in sport on perfectionism and fear of failure should include organization and doubts about actions in addition to the aspects examined in the present study. Second, we examined affective responses to success and failure using scenarios, and not actual success and failure as naturally experienced in real-life sporting competitions. To measure affective responses to success and failure we used a scenario technique that asked athletes to imagine that they experience success and failure in an important competition and then respond how they would feel. Scenarios allow researchers experimentally to manipulate emotions, and are frequently used in emotion research and in sport psychology (e.g., Grieve, Houston, Dupuis, \& Eddy, 1999). Moreover, research has shown that affective responses to scenarios closely correspond to affective responses in real life (e.g., Carver, 2004; M. D. Robinson \& Clore, 2001). Nonetheless, future studies need to show that the present findings can be replicated when affective reactions to actual success and failure in competitions are examined. Third, our mediation models were based on cross-sectional data and did not take measurement error into account, therefore, we cannot rule out reverse causal order (e.g., concern over mistakes mediating the relationship between fear of failure and affective responses) and problems with measurement error in the mediator. Consequently, future studies need to reinvestigate the present findings employing repeated-measures designs and structural equation modeling (e.g., Cole \& Maxwell, 2003) to examine the causal relationships between perfectionism, fear of failure, and affective responses to success and failure. Fourth, we did not examine athletes' attributions in the relationships between the different aspects of perfectionism, fears of failure, and affective responses to success and failure. Thus, future research may consider investigating these. Finally, the present findings may be limited to adult athletes. As the influence of parental pressure relative to coach pressure may be higher for junior athletes (where parents may have a greater influence than coaches), future research needs to investigate whether the present findings regarding 
perceived pressure generalize to junior athletes.

In conclusion, the present findings have important implications for our understanding of multidimensional perfectionism in sports as they indicate that only perfectionistic concern over mistakes and perceived pressure to be perfect show strong links with fears of failure and negative affect after failure. Perfectionistic personal standards, in contrast, were associated less with fear of failure and more with positive affect after success, indicating that only perfectionistic concerns are associated with a failure orientation, whereas perfectionistic strivings are associated with a success orientation (Frost \& Henderson, 1991; Stoeber \& Becker, 2008). Accordingly, perfectionistic strivings may form part of a healthy pursuit of excellence (Shafran, Cooper, \& Fairburn, 2002) that may eventually lead to aspired sporting performance and achievements. Perfectionistic concerns, however, need to be closely monitored in order to avoid the detrimental effect on athletes' well-being, athletic development, and competitive performance (Flett \& Hewitt, 2005; Hall, 2006), so that they do not have to fear experiencing shame and embarrassment, but may hope for success and be able to enjoy their sporting experiences and achievements. 


\section{References}

Alden, L. E., Bieling, P. J., \& Wallace, S. T. (1994). Perfectionism in an interpersonal context: A self-regulation analysis of dysphoria and social anxiety. Cognitive Therapy and Research, 18, $297-$ 316.

Amorose, A., \& Horn, T. (2000). Intrinsic motivation: Relationships with collegiate athletes' gender, scholarship status, and perceptions of their coaches' behavior. Journal of Sport \& Exercise Psychology, 22, 63-84.

Anshel, M. H., \& Eom, H. (2002). Exploring the dimensions of perfectionism in sport. International Journal of Sport Psychology, 34, 255-271.

Antony, M. M., \& Swinson, R. P. (1998). When perfect isn't good enough: Strategies for coping with perfectionism. Oakland, CA: New Harbinger.

Atkinson, J. W. (1957). Motivational determinant of risk-taking behavior. Psychological Review, 64, $359-372$.

Baron, R. M., \& Kenny, D. A. (1986). The moderator-mediator variable distinction in social psychological research: Conceptual, strategic, and statistical considerations. Journal of Personality and Social Psychology, 51, 1173-1182.

Besser, A., Flett, G. L., \& Hewitt, P. L. (2004). Perfectionism, cognition, and affect in response to performance failure vs. success. Journal of Rational-Emotive \& Cognitive-Behavior Therapy, 22, 301328.

Bieling, P. J., Israeli, A. L., \& Antony, M. M. (2004). Is perfectionism good, bad, or both? Examining models of the perfectionism construct. Personality and Individual Differences, 36, 13731385.

Bieling, P. J., Israeli, A. L., Smith, J., \& Antony, M. M. (2003). Making the grade: The behavioral consequences of perfectionism in the classroom. Personality and Individual Differences, 35, 163178. 
Brislin, R. W., Lonner, W. J., \& Thorndike, R. M. (1973). Cross-cultural research methods. New York: Wiley.

Carver, C. S. (2004). Negative affects deriving from the behavioral approach system. Emotion, 4, $3-22$.

Clements, M. (2008). Perfecting the perfectionist: Getting the balance right. Sports Coach, 30(2), $20-21$.

Cohen, J. (1992). A power primer. Psychological Bulletin, 112, 155-159.

Cole, D. A., \& Maxwell, S. E. (2003). Testing mediational models with longitudinal data:

Questions and tips in the use of structural equation modeling. Journal of Abnormal Psychology, $112,558-577$.

Conroy, D. E. (2004). The unique psychological meanings of multidimensional fears of failing. Journal of Sport \& Exercise Psychology, 26, 484-491.

Conroy, D. E., \& Metzler, J. N. (2004). Patterns of self-talk associated with different forms of competitive anxiety. Journal of Sport \& Exercise Psychology, 26, 69-89.

Conroy, D. E., Kaye, M. P., \& Fifer, A. M. (2007). Cognitive links between fear of failure and perfectionism. Journal of Rational-Emotive \& Cognitive-Behavior Therapy, 25, 237-253.

Conroy, D. E., Willow, J.P., \& Metzler, J. N. (2002). Multidimensional fear of failure measurement: The Performance Failure Appraisal Inventory. Journal of Applied Sport Psychology, 14, 76-90.

DiBartolo, P. M., Frost, R. O., Chang, P., LaSota, M., \& Grills, A. E. (2004). Shedding light on the relationship between personal standards and psychopathology: The case for contingent self-worth. Journal of Rational-Emotive \& Cognitive-Behavior Therapy, 22, 241-254.

Dunkley, D. M., Zuroff, D. C., \& Blankstein, K. R. (2003). Self-critical perfectionism and daily affect: Dispositional and situational influences on stress and coping. Journal of Personality and Social Psychology, 84, 234-252. 
Dunkley, D. M., Zuroff, D. C., \& Blankstein, K. R. (2006). Specific perfectionism components versus self-criticism in predicting maladjustment. Personality and Individual Differences, 40, 665676.

Dunn, J. G. H., Dunn, J. C., Gotwals, J. K., Vallance, J. K. H., Craft, J. M., \& Syrotuik, D. G. (2006). Establishing construct validity evidence for the Sport Multidimensional Perfectionism Scale. Psychology of Sport and Exercise, 7, 57-79.

Dunn, J. G. H., Dunn, J. C., \& Syrotuik, G. (2002). Relationship between multidimensional perfectionism and goal orientations in sport. Journal of Sport \& Exercise Psychology, 24, 376-395.

Enns, M. W., \& Cox, B. J. (2002). The nature and assessment of perfectionism: A critical analysis. In G. L. Flett, \& P. L. Hewitt (Eds.), Perfectionism: Theory, research, and treatment (pp. 33-62). Washington, DC: American Psychological Association.

Flett, G. L., \& Hewitt, P. L. (2002). Perfectionism and maladjustment: An overview of theoretical, definitional, and treatment issues. In G. L. Flett, \& P. L. Hewitt (Eds.), Perfectionism: Theory, research, and treatment (pp. 5-13). Washington, DC: American Psychological Association.

Flett, G. L., \& Hewitt, P. L. (2005). The perils of perfectionism in sports and exercise. Current Directions in Psychological Science, 14, 14-18.

Frost, R. O., Heimberg, R. G., Holt, C. S., Mattia, J. I., \& Neubauer, A. L. (1993). A comparison of two measures of perfectionism. Personality and Individual Differences, 14, 119-126.

Frost, R. O., \& Henderson, K. J. (1991). Perfectionism and reactions to athletic competition. Journal of Sport \& Exercise Psychology, 13, 323-335.

Frost, R. O., Marten, P., Lahart, C., \& Rosenblate, R. (1990). The dimensions of perfectionism. Cognitive Therapy and Research, 14, 449-468.

Gotwals, J. K., \& Dunn, J. G. H. (in press). A multi-method multi-analytic approach to establish internal construct validity evidence: The Sport Multidimensional Perfectionism Scale 2. Measurement in Physical Education and Exercise Science. 
Gould, D., Dieffenbach, K., \& Moffett, A. (2002). Psychological characteristics and their development in Olympic champions. Journal of Applied Sport Psychology, 14, 172-204.

Gould, D., Horn, T., \& Spreeman, J. (1983). Sources of stress in junior elite wrestlers. Journal of Sport Psychology, 5, 159-171.

Gould, D., Tuffey, S., Udry, E. \& Loehr, J. (1996). Burnout in competitive junior tennis players: II. Qualitative analysis. The Sport Psychologist, 10, 341-366.

Gould, D., Udry, E., Tuffey, S., \& Loehr, J. (1996). Burnout in competitive junior tennis players: I. A quantitative psychological assessment. The Sport Psychologist, 10, 322-340.

Grieve, F. G., Houston, D. A., Dupuis, S. E., \& Eddy, D. (1999). Counterfactual production and achievement orientation in competitive athletic settings. Journal of Applied Social Psychology, 29, 2177-2202.

Hall, H. K. (2006). Perfectionism: A hallmark quality of world class performers, or a psychological impediment to athletic development? In D. Hackfort \& G. Tenenbaum (Eds.), Essential processes for attaining peak performance (Vol. 1, pp. 178-211). Oxford, UK: Meyer \& Meyer.

Hewitt, P. L., \& Flett, G. L. (1991). Perfectionism and self and social contexts: Conceptualization, assessment, and association with psychopathology. Journal of Personality and Social Psychology, 60, 456-470.

Hewitt, P. L., Flett, G. L., Besser, A., Sherry, S. B., \& McGee, B. J. (2003). Perfectionism is multidimensional: A reply to Shafran, Cooper, and Fairburn. Behaviour Research and Therapy, 41, 1221-1236.

Kaye, M. P., Conroy, D. E., \& Fifer, A. M. (2008). Individual differences in incompetence avoidance. Journal of Sport \& Exercise Psychology, 30, 110-132.

Klibert, J. J., Langhinrichsen Rohling, J., \& Saito, M. (2005). Adaptive and maladaptive aspects of self-oriented versus socially prescribed perfectionism. Journal of College Student Development, 46, $141-156$. 
Koivula, N., Hassmen, P., \& Fallby, J. (2002). Self-esteem and perfectionism in elite athletes: Effects on competitive anxiety and self-confidence. Personality and Individual Differences, 32, 865875.

Lazarus, R. S. (1991). Emotion and adaptation. New York: Oxford University.

Lewis, M. (1992). Shame: The exposed self. New York: Free Press.

Lewthwaite, R., \& Scanlan, T. K. (1989). Predictors of competitive trait anxiety in male youth sport participants. Medicine \& Science in Sports \& Exercise, 21, 221-229.

Lundh, L.-G., Saboonchi, F., \& Wångby, M. (2008). The role of personal standards in clinically significant perfectionism. A person-oriented approach to the study of patterns of perfectionism. Cognitive Therapy and Research, 32, 333-350.

Lutwak, N., \& Ferrari, J. R. (1996). Moral affect and cognitive processes: Differentiating shame from guilt among men and women. Personality and Individual Differences, 21, 891-896.

McClelland, D. C., Atkinson, J. W., Clark, R. A., \& Lowell, E. L. (1953). The achievement motive. New York: Appleton-Century-Croft.

McGregor, H. A., \& Elliot, A. J. (2005). The shame of failure: Examining the link between fear of failure and shame. Personality and Social Psychology Bulletin, 31, 218-231.

Molnar, D. S., Reker, D. L., Culp, N. A., Sadava, S. W., \& DeCourville, N. H (2006). A mediated model of perfectionism, affect, and physical health. Journal of Research in Personality, 40, 482-500.

Nezlek, J. B. (2005). Distinguishing affective and non-affective reactions to daily events. Journal of Personality, 73, 1539-1568.

Nunnally, J. C., \& Bernstein, I. H. (1994). Psychometric theory (3rd ed.). New York: McGraw-Hill.

Parkinson, B., \& Manstead, A. S. (1993). Making sense of emotion in stories and social life. Cognition and Emotion, 7, 295-323.

Pelletier, L. G., Fortier, M. S., Vallerand, R. J., \& Briere, N. M. (2001). Associations among perceived autonomy support, forms of self-regulations, and persistence: A prospective study. Motivation and Emotion, 25, 279-306. 
Pleva, J., \& Wade, T. D. (2007). Guided self-help versus pure self-help for perfectionism: A randomised controlled trial. Behaviour Research and Therapy, 45, 849-861.

Preacher, K. J., \& Hayes, A. F. (2004). SPSS and SAS procedures for estimating indirect effects in simple mediation models. Behavior Research Methods, Instruments, \& Computers, 36, 717-731.

Robinson, M. D., \& Clore, G. L. (2001). Simulation, scenarios, and emotional appraisal: Testing the convergence of real and imagined reactions to emotional stimuli. Personality and Social Psychology Bulletin, 27, 1520-1532.

Robinson, T. T., \& Carron, A. V. (1982). Personal and situational factors associated with dropping out versus maintaining participating in competitive sport. Journal of Sport Psychology, 4, 364-378.

Sagar, S. S., Lavallee, D., \& Spray, C. M. (2007). Why young elite athletes fear failure: Consequences of failure. Journal of Sports Sciences, 25, 1171-1184.

Sagar, S. S., Lavallee, D., \& Spray, C. M. (2009). Coping with the effects of fear of failure: A preliminary investigation of young elite athletes. Journal of Clinical Sport Psychology, 3, 1-27.

Schmalt, H. D. (1982). Two concepts of fear of failure. In R. Schwarzer, H. Van Der Ploeg, \& C. D. Spielberger (Eds.), Advances in test anxiety research (Vol. 1, pp. 45-52). Lisse: Swets.

Shafran, R., Cooper, Z., \& Fairburn, C. G. (2002). Clinical perfectionism: A cognitive-behavioural analysis. Behaviour Research and Therapy, 40, 773-791.

Shrout, P. E., \& Bolger, N. (2002). Mediation in experimental and nonexperimental studies: New procedures and recommendations. Psychological Methods, 7, 422-445.

Smith, R. E., \& Smoll, F. L. (2007). Social-cognitive approach to coaching behaviors. In S. Jowett, \& D. Lavallee (Eds.), Social psychology in sport (pp. 75-90). Champaign, IL: Human Kinetics.

Stöber, J. (1998). The Frost Multidimensional Perfectionism Scale: More perfect with four (instead of six) dimensions. Personality and Individual Differences, 24, 481-491. 
Stoeber, J., \& Becker, C. (2008). Perfectionism, achievement motives, and attribution of success and failure in female soccer players. International Journal of Psychology, 43, 980-987.

Stoeber, J., \& Eismann, U. (2007). Perfectionism in young musicians: Relations with motivation, effort, achievement, and distress. Personality and Individual Differences, 43, 2182-2192.

Stoeber, J., Kempe, T., \& Keogh, E. J. (2008). Facets of self-oriented and socially prescribed perfectionism and feelings of pride, shame, and guilt following success and failure. Personality and Individual Differences, 44, 1506-1516.

Stoeber, J., \& Otto, K. (2006). Positive conceptions of perfectionism: Approaches, evidence, challenges. Personality and Social Psychology Review, 10, 295-319.

Stoeber, J., Otto, K., Pescheck, E., Becker, C., \& Stoll, O. (2007). Perfectionism and competitive anxiety in athletes: Differentiating striving for perfection and negative reactions to imperfection. Personality and Individual Differences, 42, 959-969.

Stoeber, J., Otto, K., \& Stoll, O. (2004). Mehrdimensionales Inventar zu Perfektionismus im Sport (MIPS) [Multidimensional Inventory of Perfectionism in Sport (MIPS)]. In J. Stoeber, K. Otto, E. Pescheck, \& O. Stoll (Eds.), Skalendokumentation "Perfektionismus im Sport" (Hallesche Berichte zur Pädagogischen Psychologie No. 7, pp. 4-13). Halle/Saale, Germany: University of Halle-Wittenberg.

Stoeber, J., Otto, K., \& Stoll, O. (2005). Multidimensional Inventory of Perfectionism in Sport (MIPS). Unpublished manuscript, University of Kent, UK.

Stoeber, J., \& Rennert, D. (2008). Perfectionism in school teachers: Relations with stress appraisals, coping styles, and burnout. Anxiety, Stress, \& Coping, 21, 37-53.

Stoeber, J., Stoll, O., Pescheck, E., \& Otto, K. (2008). Perfectionism and achievement goals in athletes: Relations with approach and avoidance orientations in mastery and performance goals. Psychology of Sport and Exercise, 9, 102-121. 
Stoeber, J., Stoll, O., Salmi, O, \& Tiikkaja, J. (2009). Perfectionism and achievement goals in young Finnish ice-hockey players aspiring to make the Under-16 national team. Journal of Sports Sciences, 27, 85-94.

Stoll, O., Lau, A., \& Stoeber, J. (2008). Perfectionism and performance in a new basketball training task: Does striving for perfection enhance or undermine performance? Psychology of Sport and Exercise, 9, 620-629.

Stumpf, H., \& Parker, W. D. (2000). A hierarchical structural analysis of perfectionism and its relation to other personality characteristics. Personality and Individual Differences, 28, 837-852.

Tabachnick, B. G., \& Fidell, L. S. (2007). Using multivariate statistics (5th ed.). Boston, MA: Pearson. Tangney, J. P. (2002). Perfectionism and the self-conscious emotions: Shame, guilt, embarrassment and pride. In G. L. Flett, \& P. L. Hewitt (Eds.), Perfectionism: Theory, research, and treatment (pp. 199-216). Washington, DC: American Psychological Association.

Teevan, R., \& McGhee, P. (1972). Childhood development of fear of failure motivation. Journal of Personality and Social Psychology, 21, 345-348.

Underwood, J. (1978). Taking the fun out of a game. In R. Martens (Ed.), Joy and sadness in children's sports (pp. 50-64). Champaign, IL: Human Kinetics.

Vallance, J. K., Dunn, J. G. H., \& Dunn, J. L. (2006). Perfectionism, anger, and situation criticality in competitive youth ice hockey. Journal of Sport \& Exercise Psychology, 28, 383-406.

Wilson, G. V., \& Kerr, J. H. (1999). Affective responses to success and failure: A study of winning and losing in competitive rugby. Personality and Individual Differences, 16, 85-99. 


\section{Table 1}

Correlations of Perfectionism, Fear of Failure, and Affect

\begin{tabular}{|c|c|c|c|c|c|c|c|c|c|c|c|c|c|}
\hline Variable & $M$ & $S D$ & $\alpha$ & 1 & 2 & 3 & 4 & 5 & 6 & 7 & 8 & 9 & 10 \\
\hline \multicolumn{14}{|l|}{ Perfectionism } \\
\hline 1. Personal standards & 4.64 & 0.97 & .80 & & & & & & & & & & \\
\hline 2. Concern over mistakes & 3.90 & 1.09 & .81 & $.56^{* * *}$ & & & & & & & & & \\
\hline 4. Perceived coach pressure & 3.46 & 1.47 & .95 & $.34 * * *$ & $.39 * * *$ & $.51^{* * *}$ & & & & & & & \\
\hline \multicolumn{14}{|l|}{ Fears of failure } \\
\hline $\begin{array}{l}\text { 5. Fear of experiencing shame and } \\
\text { embarrassment }\end{array}$ & 2.01 & 0.81 & .84 & $.20 * * *$ & $.51 * * *$ & $.20 * * *$ & $.29 * * *$ & & & & & & \\
\hline 6. Fear of devaluing one's self-estimate & 1.74 & 0.81 & .70 & $.21 * * *$ & $.46^{* * *}$ & $.18^{* * *}$ & $.12^{*}$ & $.67^{* * *}$ & & & & & \\
\hline 7. Fear of important others losing interest & 1.39 & 0.86 & .85 & $.23 * * *$ & $.45^{* * *}$ & $.24 * * *$ & $.25^{* * *}$ & $.67 * * *$ & $.43^{* * *}$ & & & & \\
\hline \multicolumn{14}{|l|}{ Affect } \\
\hline 10. Positive affect after success & 2.96 & 0.54 & .76 & $.11 *$ & .02 & -.01 & $.12^{*}$ & .05 & -.02 & -.05 & -.03 & -.05 & \\
\hline 11. Negative affect after failure & 2.15 & 0.79 & .85 & $.11^{*}$ & $.30 * * *$ & $.11 *$ & $.21 * * *$ & $.48^{* * *}$ & $.35^{* * *}$ & $.26 * * *$ & $.29 * * *$ & $.20 * * *$ & $.23^{* * *}$ \\
\hline
\end{tabular}

Note. $N=388$. All scores are mean scores with perfectionism scores having a possible range of 1-7 ("strongly disagree"-"strongly agree"), fear of failure scores 0-4 ("I don't believe it at all"-'I believe it 100\% of the time"), and affect scores 0-4 ("not at all"-"extremely").

${ }^{*} p<.05 . * * p<.01 . * * * p<.001$. 
Table 2

Summary of Regression Analyses for Perfectionism Predicting Fears of Failure: Standardized Regression Coefficients and Model Summaries

\begin{tabular}{|c|c|c|c|c|c|}
\hline Personal standards & $-.14 * *$ & -.05 & -.05 & .02 & .10 \\
\hline Concern over mistakes & $.55^{* * *}$ & $.51 * * *$ & $.42^{* * *}$ & $.37 * * *$ & $.32^{* * *}$ \\
\hline Perceived parental pressure & -.03 & .06 & .07 & $.17 * * *$ & $.14^{* *}$ \\
\hline$R^{2}$ & $.29 * * *$ & $.22 * * *$ & $.21 * * *$ & $.32 * * *$ & $.20 * * *$ \\
\hline$R^{2}$ adjusted & $.28 * * *$ & $.21 * * *$ & $.20^{* * *}$ & $.32 * * *$ & $.19^{* * *}$ \\
\hline
\end{tabular}

Note. $N=388$.

$* * p<.01 . * * * p<.001$. 
Table 3

Summary of Regression Analyses for Perfectionism Predicting Affective Responses:

Standardized Regression Weights and Model Summaries

\begin{tabular}{lcc}
\hline Predictor & $\begin{array}{c}\text { Positive affect } \\
\text { after success }\end{array}$ & $\begin{array}{c}\text { Negative affect } \\
\text { after failure }\end{array}$ \\
\hline Personal standards & $.13^{*}$ & -.10 \\
Concern over mistakes & -.08 & $.32^{* * *}$ \\
Perceived parental pressure & -.09 & -.05 \\
Perceived coach pressure & $.16^{* *}$ & $.14^{*}$ \\
$R^{2}$ & .03 & $.11^{* * *}$ \\
$R^{2}$ adjusted & .02 & $.10^{* * *}$
\end{tabular}

Note. $N=388$.

${ }^{*} p<.05 .{ }^{* *} p<.01 .{ }^{* * *} p<.001$. 
Table 4

Summary of Regression Analyses for Fear of Failure Predicting Affective Responses:

Standardized Regression Weights and Model Summaries

\begin{tabular}{lcc}
\hline Predictor & $\begin{array}{c}\text { Positive affect } \\
\text { after success }\end{array}$ & $\begin{array}{c}\text { Negative } \\
\text { affect } \\
\text { after failure }\end{array}$ \\
\hline Fear of experiencing shame and embarrassment & $.23^{* *}$ & $.52^{* * *}$ \\
Fear of devaluating one's self-estimate & -.08 & .04 \\
Fear of important others losing interest & -.14 & -.13 \\
Fear of upsetting important others & -.03 & .05 \\
Fear of having an uncertain future & -.04 & .00 \\
$\mathrm{R}^{2}$ & .02 & $.24^{* * *}$ \\
$\mathrm{R}^{2}$ adjusted & .01 & $.23^{* * *}$ \\
\hline
\end{tabular}

Note. $N=388$.

${ }^{* *} p<.01 .{ }^{* * *} p<.001$. 


\section{Figure Caption}

Figure 1. $N=$ 388. Panel A: Fear of experiencing shame and embarrassment fully mediates the relationship between perfectionistic personal standards and negative affect after failure; $R^{2}$ model $=.24$, adjusted $R^{2}=.23$, both $p$ s $<.001$. Panel B: Fear of experiencing shame and embarrassment fully mediates the relationship between perceived coach pressure and negative affect after failure; $R^{2}$ model $=.24$, adjusted $R^{2}=.24$, both $p$ s $<.001 .{ }^{* * *} p<.001$. 
A

Concern over mistakes

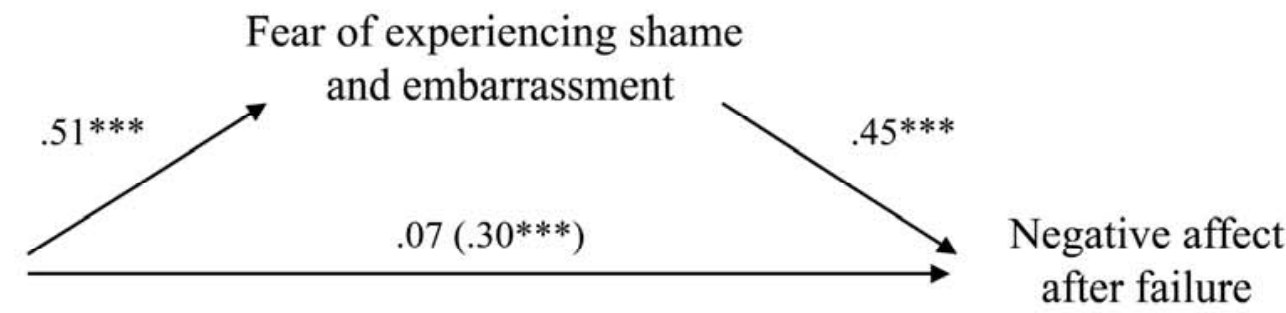

$$
\text { B }
$$

Perceived coach pressure

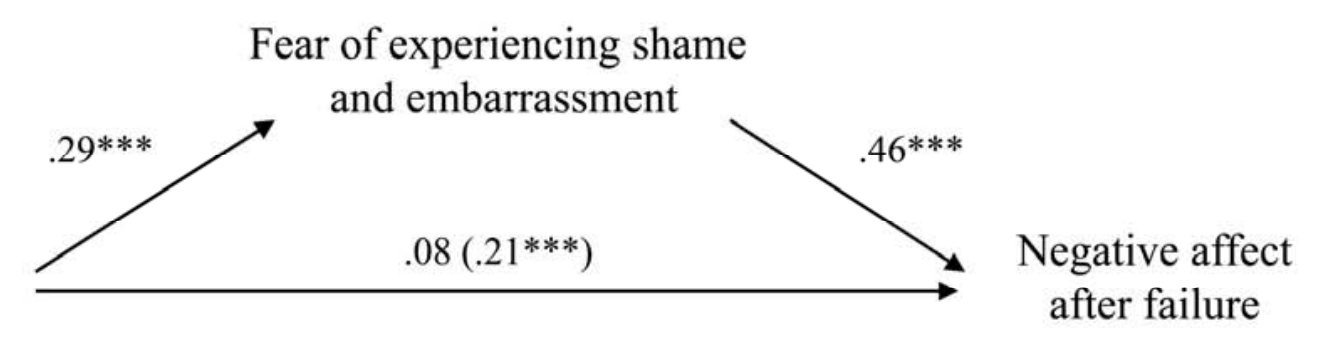


Appendix

MIPS Perceived Pressure Scales and Items (Stoeber et al., 2005)

Perceived Parental Pressure

My parents expect my performance to be perfect.

My parents criticize everything I don't do perfectly.

My parents are dissatisfied with me if my performance is not top class.

My parents expect me to be perfect.

My parents demand nothing less than perfection of me.

My parents make extremely high demands of me.

My parents set extremely high standards for me.

My parents are disappointed in me if my performance is not perfect.

Perceived Coach Pressure

My coach expects my performance to be perfect.

My coach criticizes everything I don't do perfectly.

My coach is dissatisfied with me if my performance is not top class.

My coach expects me to be perfect.

My coach demands nothing less than perfection of me.

My coach makes extremely high demands of me.

My coach sets extremely high standards for me.

My coach is disappointed in me if my performance is not perfect. 